\title{
Prevalence, belief and awareness of preferring traditional healthcare system in urban and rural people of Noakhali district, Bangladesh
}

\author{
*Palash Karmakar ${ }^{1}$, Muhammad Mazharul Islam¹, Md. Golam Kibria ${ }^{1}$, Mohammad Salim Hossain ${ }^{1}$, \\ Mohammad Mafruhi Sattar ${ }^{2}$ \\ ${ }^{1}$ Department of Pharmacy, Noakhali Science and Technology University, Sonapur, Noakhali-3814, Bangladesh \\ ${ }^{2}$ Department of Pharmacy, Jahangirnagar University, Savar, Dhaka-1342, Bangladesh
}

\begin{abstract}
Healthcare systems contribute a major role in maintaining good health. The study was conducted to analyze the prevalence, belief and awareness of preferring traditional healthcare systems in urban and rural people of Noakhali district of Bangladesh. Data were collected randomly from 400 respondents aging 20 to 60 years by personal interviewing with a well structured questionnaire during October 20, 2011 to December 20, 2011. Study stated that, overall $79 \%$ of the respondents were found to feel comfortable in using traditional healthcare system whereas only $21 \%$ prefer the modern system. Urban people showed their belief mostly in homeopathy (23\%), ayurvedic/unani (18\%) and herbal medicine $(17 \%)$ of traditional healthcare system whereas Kaviraji $(27 \%)$, herbal medicine $(18 \%)$ and spiritual healing $(11 \%)$ were the systems on which rural people showed their much faith and belief for the treatment of different ailments. Jaundice and sexual problems were the two dominant disease conditions for which traditional healthcare systems were most preferred by the respondents. Beside these $68 \%$ of urban and $88 \%$ of rural as well as $57.64 \%$ of educated and $97.82 \%$ of uneducated respondents were not aware about the appropriate healthcare system for different diseases. Belief in no side effect and safe remedy, mass population of the study area preferred different traditional healthcare systems but most of them were not aware about the exact therapy.
\end{abstract}

Key Words: Traditional healthcare system, belief, urban, rural, Noakhali.

\section{INTRODUCTION}

Healthcare system is a medical practice that provides medical and other healthcare services to the people. Healthcare services differ in their attitude and idea as to the causes of disease, their therapeutic approach of healing, treatment methods, composition and preparation of drug products. The existing healthcare system in Bangladesh can be generally classified into two as traditional and modern systems (Banglapedia, 2006).

Traditional system is an art of remedial based on traditional use of plants, animals or other natural origin, cultural behaviour, social practices, spiritual beliefs and superstitions of the present and earlier

\footnotetext{
*Corresponding Author:

Palash Karmakar, Lecturer

Department of Pharmacy

Noakhali Science and Technology University

Sonapur, Noakhali-3814, Bangladesh.

E-mail:pknstu@gmail.com

Contact No.: +88 - 01717036968
}

generations of people in many cases (Banglapedia, 2006). Practices of traditional medicine have been adopted in different regions and cultures without the equivalent advancement of international standards and methods for assessment. For primary health care, $80 \%$ population of some Asian and African countries, depend on traditional medicine and it is now a recognized system of medical practice in this region and in some communities it has been used for thousands of years (WHO, 2008 and Banglapedia, 2006).

Beside some Asian countries like India and China, traditional system is now a modernized system and practiced side by side with modern allopathic medicine as an alternative and supplementary system of medicine in Bangladesh. Now some of the traditional medicines are prepared by using both indigenous and modern pharmaceutical technology under a strict quality control procedures. Ayurvedic, unani, homeopathic, folk medicines etc. are 
practiced as traditional healthcare systems in Bangladesh (Banglapedia, 2006).

Noakhali is one of the coastal and south-eastern districts of Bangladesh consisting of 9 upazilas, 5 municipalities, 45 wards, 90 mahallas, 83 union parishads, 909 mouzas and 978 villages. Being exposed to the Bay of Bengal Noakhali is prone to multiple hazards like high tidal bore, tornado, flood, cyclone etc. and some causes enormous destruction (NCAP Bangladesh, 2012 and LGED Noakhali, 2011). $60 \%$ people of this district live under poverty line of which $53 \%$ are landless poor (PRAN, 2009). Agriculture contributes about $40 \%$ of the regional GDP where $80 \%$ of the populations are involved in the sector. Fishing is also a dominant employment for the extreme poor and poor people. Noakhali is ahead significantly in case of educational facilities as university, medical college, textile college, agricultural institution etc. are available and $69.50 \%$ of total population are literate (LGED Noakhali, 2011).

The aim of this study was to investigate the prevalence, belief and awareness on traditional healthcare system to the people of urban and rural area of Noakhali district of Bangladesh. Due to a coastal district with poverty but better rate of literacy have made this district a choice of our study. It was not intended to measure the outcomes of traditional medicine use; rather it was designed to measure attitudes about the medicine of traditional systems among the people.

\section{MATERIALS AND METHODS}

\section{Study Design}

Study was conducted to evaluate the prevalence, belief and awareness on traditional healthcare system to the people of urban and rural area of Noakhali district of Bangladesh by collecting both qualitative and quantitative data randomly through a survey using a structured questionnaire as the principal tool. The questionnaire was in three parts. The first part gathered socio-demographic information of respondents such as age distribution, gender, educational status and income level. The second part collected information on general practice of various traditional healthcare systems in the study area and the disease pattern for which respondents use traditional system, whilst the third part tried to identify the awareness and belief of mass people about their preferred medication system.

\section{Study Area}

The study was done among the people of Noakhali district dividing in two groups as urban and rural area. Noakhali municipality, Choumuhani of Begumganj upazila, Kabirhat municipality and town area of Senbag upazila were considered as urban areas. On the other hand 95 Noakhali mouza of Noakhali sadar upazila, Eklashpur union of Begumganj upazila, Sonaimuri upazila, Subarna Char upazila, Burrir char union of Hatia upazila were considered as rural part of the study area during the survey (Ahmad, 2005). The areas were separated on the basis of infrastructure and socioeconomic condition of the area. The study areas were selected according to distance, easy travelling, and density of population to survey.

\section{Sample Size}

For the study, the data were collected randomly from 200 respondents in urban area and 200 from rural area. So the sample size was 400 . In both of the areas both male and female people were surveyed.

\section{Data Collection}

After preparing the questionnaire, primary data were collected from the target sites during October 20, 2011 to December 20, 2011. The respondents were asked to verbally answer a structured questionnaire. The primary data were collected from the respondents in face-to-face interview. The questions were asked systemically in a very simple manner and the information was recorded on the survey schedule.

\section{Inclusion and exclusion criteria}

The respondents who were easily reachable, especially at bazaar, market, bus station, health institutions, physicians practice places and other crowdie places were included. On the other hand people who were in house, at office and did not cooperate for survey were excluded. Male respondents were more cooperative than female that's why majority of the respondents were male. Women who showed restriction to conversation were excluded. Children and very old people were also excluded from the study. In the survey respondents' age, 
Table 1: General belief (\%) on preferring specific traditional system of the respondents in urban and rural area.

\begin{tabular}{lcc|cc}
\hline \multirow{2}{*}{ Traditional } & \multicolumn{2}{c|}{ Urban (n1= 200) } & \multicolumn{2}{c}{ Rural (n2= 200) } \\
\cline { 2 - 5 } systems & $\begin{array}{c}\text { No. of } \\
\text { respondents }\end{array}$ & $\begin{array}{c}\text { Rate } \\
\mathbf{( \% )}\end{array}$ & $\begin{array}{c}\text { No. of } \\
\text { respondents }\end{array}$ & $\begin{array}{c}\text { Rate } \\
\mathbf{( \% )}\end{array}$ \\
\hline Ayurvedic/Unani & 36 & 18 & 6 & 3 \\
Spiritual Healing & 12 & 6 & 22 & 11 \\
Herbal Medicine & 34 & 17 & 36 & 18 \\
Homeopathy & 46 & 23 & 18 & 9 \\
Kaviraji & 18 & 9 & 54 & 27 \\
Hypnosis & 6 & 3 & 16 & 8 \\
Others & 14 & 7 & 6 & 3 \\
Never Used & 34 & 17 & 0 & 0 \\
\hline
\end{tabular}

$\mathrm{n} 1=$ Total number of respondents in urban area, $\mathrm{n} 2=$ Total

number of respondents in rural area

education and socioeconomic conditions were considered as including criteria.

\section{Data processing and analysis}

After collection, all the data were summarized and scrutinized carefully and then recorded. Finally, relevant tables and graphs were prepared in accordance with the objectives of the study. Microsoft Office Excel® 2007 program was used for data processing and analysis.

\section{RESULTS AND DISCUSSION}

Overall prevalence and belief of preferring traditional system

In the study, most of the respondents were being to be highly motivated to use traditional medicine in the study area. About 79\% respondents felt comfortable to use traditional medicine because they believed that it is free from side effects and cheaper than modern medicine. Only 21\% respondents preferred modern medicine. The possible reason behind this variation might be the reason of increasing global interest towards traditional medicines over the conventional treatment due to safe and well tolerated remedies even in chronic illness (Vyawahare et al., 2009) (Figure 1).

\section{General belief of respondents on various tradi- tional systems}

Health-seeking behavior is the progression of remedial actions that individuals undertake to rectify professed ill health (Ward et al., 1996). In the study, six main categories of traditional systems were found to uses by the respondents of both in urban and rural areas which were categorized as

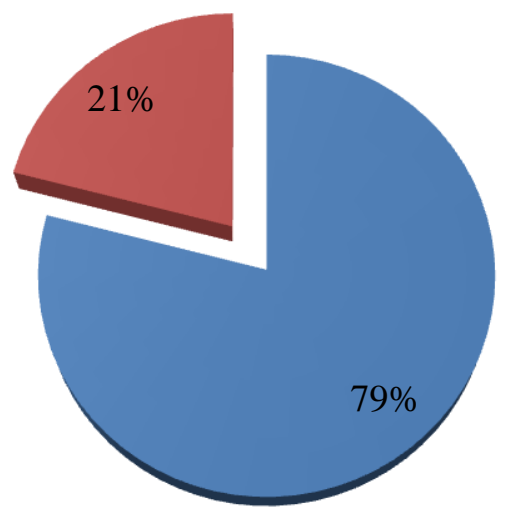

- Traditional medicine $\quad$ Modern medicine

Figure 1: Percentage (\%) of overall belief of respondents of preferring traditional and modern medicine in the study area.

ayurvedic/unani, spiritual healing, herbal medicine, homeopathy, kaviraji and hypnosis. From the survey, it was found that the most preferred medication system among the majority of respondents in urban area was homeopathy which is one of the most widely established and safe forms of traditional system practiced worldwide (Shah et al., 2010). After homeopathy, ayurvedic/unani and herbal systems of traditional medicine, which were extensively practiced all over the country (Islam, 2004) were also found the choice of preference to the urban people followed by kaviraji, spiritual healing, hypnosis and others. A group of respondents were also found who never used any traditional medicine in the urban area. An opposite scenario was observed in case of rural people as they showed their much faith for their treatment in kaviraji, a treatment system practiced by folk practitioner (Shaheen et al., 2010). This might be due to the perception of low cost and less side effects of that system (Shaheen et al., 2010). They also showed almost similar interest like urban people on herbal medicine which is playing a major role in the health of the millions of people globally (Harun-Or-Rashid et al., 2011). Study also reports that rural people showed their preference more on a religious non-scientific method of treatment called spiritual healing than homeopathy and ayurvedic/unani treatment (Harun-Or-Rashid et al., 2011). Some people were also found to prefer hypnosis in rural area. Overall, rural people were found more, than urban people 
Table 2: Percentage (\%) of awareness of appropriate healthcare system in urban, rural, educated and uneducated respondents of the study area.

\begin{tabular}{|c|c|c|c|c|}
\hline \multirow[b]{2}{*}{$\begin{array}{l}\text { Respondents } \\
\text { category }\end{array}$} & \multicolumn{2}{|l|}{ Aware } & \multicolumn{2}{|c|}{ Unaware } \\
\hline & $\begin{array}{c}\text { No. of } \\
\text { respondents }\end{array}$ & $\begin{array}{c}\text { Rate } \\
(\%)\end{array}$ & $\begin{array}{c}\text { No. of } \\
\text { respondents }\end{array}$ & $\begin{array}{c}\text { Rate } \\
(\%)\end{array}$ \\
\hline Urban (n1=200) & 64 & 32 & 136 & 68 \\
\hline Rural (n2=200) & 24 & 12 & 176 & 88 \\
\hline Educated (n3=170) & 72 & 42.35 & 98 & 57.64 \\
\hline Uneducated $(\mathrm{n} 4=230)$ & 5 & 2.17 & 225 & 97.82 \\
\hline
\end{tabular}

for preferring the traditional systems, some of which have not any scientific basis such as spiritual healing. The possible reason might be lack of medical equipments and scarcity of qualified physicians, lower infra-structural facilities, benefits of modern healthcare system cannot be extended to rural areas as needed and higher healthcare cost of modern medical system (Banglapedia, 2006) (Table 1).

\section{Disease conditions for which respondents prefer traditional healthcare systems}

In the study area, mainly nine types of diseases such as sexual problems, jaundice, kidney and urinary diseases, fungal infections, joint and back pain, infectious diseases, skin diseases, respiratory diseases and diarrheal diseases were found for which respondents of both urban and rural areas showed their preference for choosing traditional system for the treatment. A significant portion of the respondents of both urban and rural area utilized traditional medicines mainly for jaundice and sexual problems and felt comfortable to go to traditional practitioner because they considered that traditional medicines were more effective than modern one particularly for those diseases. The scenario of preferring traditional remedies for both of jaundice and sexual problems were higher in rural respondents than urban though urban respondents showed similar preference of traditional system for jaundice. The reason behind this might be the unavailability of unique treatment for jaundice and over advertising of traditional medicines in the treatment of sexual diseases (Abbasi, 2009 ; Islam and Farah, 2008). Beside those two diseases, rural people were also more dominant towards traditional remedies than urban people in the treatment of
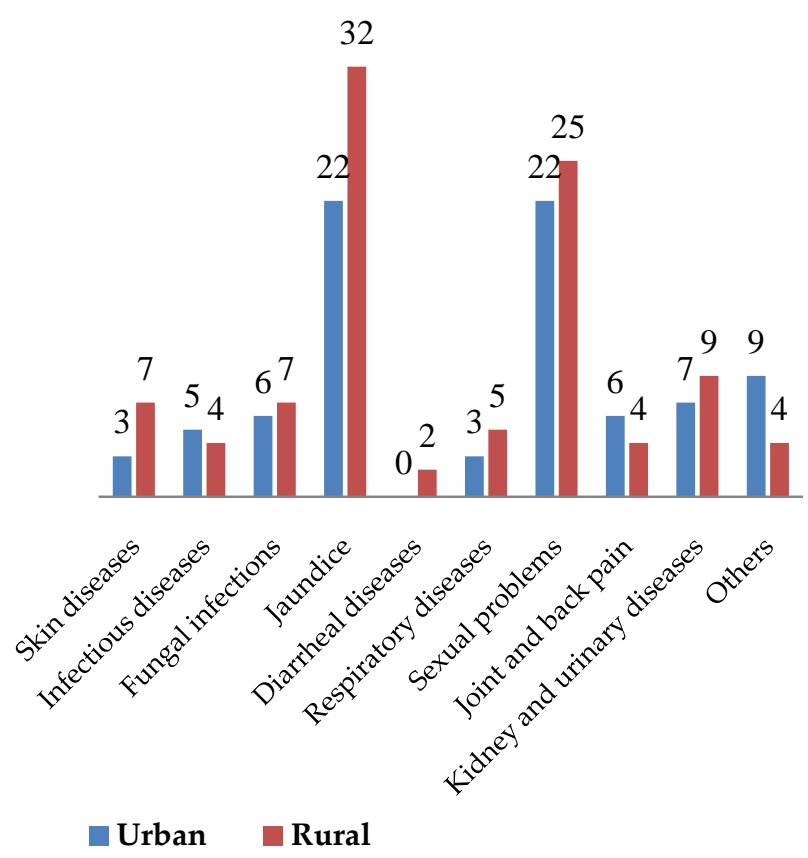

Figure 2: Percentage (\%) of the respondents preferring traditional healthcare systems in different disease conditions. Numeric value over the bar indicates the percentage of choice of traditional healthcare system on different disease conditions in the urban and rural part of the study area.

kidney and urinary diseases, skin diseases, respiratory diseases and fungal infections possibly due to the traditional dependency of rural population on folk medicinal healers for the treatment of their ailments in Bangladesh (Hossan et al., 2010). Joint and back pain and infectious diseases were the two ailments where urban people showed more treatment seeking attitude to traditional systems over rural people. Except a few portion of rural people, no urban people were found to prefer traditional medicine to treat diarrheal disease, a common health problem in Bangladesh (Yanan, 2009) (Figure 2).

\section{Awareness of the respondents about the appropri- ate healthcare system}

The study stated that though traditional medicines were frequently used by a large portion of the studied respondents of both urban and rural areas but majority of them have a little awareness about the correct medication system. Unluckily more than half of the total educated respondents were also found unaware about the systems of treatment. On the other hand, except a very few uneducated respondents all were also totally unaware about the 
appropriate healthcare system. Most of the uneducated people showed strange belief that traditional medicines are more effective than the modern medicines as their sources involve natural plants and herbs that have had a distinctive place in all the civilizations all over the world (Joshi et al., 2012) or other origin which are better than the medicine given by the qualified physician. The probable reason might be the lacking of sufficient healthcare services in Bangladesh (Islam and Aktar, 2011) (Table 2).

The study showed that majority of people preferred traditional healthcare system for their ailments but awareness was very low. Like arsenic, awareness can be increased through the government and non government program by using electronic media, mass media, print media etc. (Uddin et al., 2011).

\section{CONCLUSION}

Medicines and medication systems are the media for ensuring physical wellbeing. No doubt only the proper healthcare system can cure a disease effectively. In Bangladesh though modern health facilities and qualified physicians are available but many people still believe in different traditional systems for the cure and prevention of their ailments. The findings of the study are threatening because majority of the people of both urban and rural part in the study area have shown their preference and belief towards traditional systems than modern healthcare facilities. Not only uneducated but also educated people have not sufficient knowledge and awareness about the proper medication system. Most of the people possess a strange belief that traditional medicines are safe and free from side effects where preparation and dosage of some traditional systems are not scientific. In maximum cases people are influenced of taking unscientific or wrong medicines through vigorous advertisements of traditional medicine manufacturers mainly in the rural area. Probably lack of education, unawareness about healthcare systems, poverty, non-availability and high fees of physicians, negligence of minor ailments, undeveloped medical service and superstitions in some cases may also responsible for giving preference in taking different traditional medicines. Though some traditional healthcare systems like ayuvedic, herbal and homeopathy are popular and trying to ensure ethical practice but others such as kaviraji, spiritual healing, hypnosis and street medicine seller do not maintain any ethics and it can create serious health hazards any time. In reality, there is no mechanism or legislation exists in this area to protect these types of unethical business. As traditional healthcare systems are still the preferable choice in many people and available with modern medical facilities, their use should be scientific and people should be much educated and aware on them because a little mistake can leads to a fatal outcome. In future more study can be conducted to re-evaluate the using pattern of different healthcare systems for the betterment of the people in this area.

\section{REFERENCES}

Abbasi, A.M., Khan, M.A., Ahmad, M., Zafar, M., Khan, H., Muhammad, N. and Sultana, S. (2009). Medicinal plants used for the treatment of jaundice and hepatitis based on socio-economic documentation. African Journal of Biotechnology, 8 (8):1643-1650.

Ahmad, M. (2005). Living in the coast, Urbanization. PDOICZMP (Program Development Office for Integrated Coastal Zone Management Plan).Water Resources Planning Organization (WARPO), Ministry of Water Resources, Government of the People's Republic of Bangladesh.

Banglapedia (National Encyclopedia of Bangladesh). (2006). Healthcare system. [Link] [Accessed on 05.06.2012].

Harun-Or-Rashid, M., Yoshida, Y., Rashid, M.A., Nahar, S. and Sakamoto, J. (2011). Perceptions of the Muslim religious leaders and their attitudes on herbal medicine in Bangladesh: a cross-sectional study. BMC Research Notes, 4(366): 1-9. [DOI]

Hossan, M.S., Hanif, A., Agarwala, B., Sarwar, M.S., Karim, M., Taufiq-Ur-Rahman, M., Jahan, R. and Rahmatullah, M. (2010). Traditional use of medicinal plants in Bangladesh to treat urinary tract infections and sexually transmitted diseases. Ethnobotany Research \& Applications, 8: 061-074. [DOI]

Islam, H.R. (2004). Present status of herbal medicine in Bangladesh. Regional Training Course on :"Herbal drug industry for compliance to quality parameters", New Delhi, India.

Islam, M.S. and Aktar, S. (2011). Measuring physical accessibility to health facilities - A case study on Khulna city. World Health \& Population, 12(3).

Islam, M.S. and Farah, S.S. (2008). How Complementary and Alternative Medicine (CAM) is promoted in Bangladesh?: A critical evaluation of the advertisements published in 
local newspapers. The Internet Journal of Alternative Medicine, 5 (2).

Joshi, M., Gaonkar, K., Mangoankar, S. and Satarkar, S. (2012). Pharmacological investigation of Areca catechu extracts for evaluation of learning, memory and behavior in rats. International Current Pharmaceutical Journal, 1(6): 128-132. DOI: [DOI]

LGED Noakhali. (2011). About Noakhali. [Link] [Accessed on 05.06.2012]

NCAP Bangladesh. (2012). Description of Noakhali district. [Link] [Accessed on 05.06.2012].

Participatory Research \& Action Network-PRAN. (2009). Save our people's; who's are affected by cyclone Aila. [Link] [Accessed on 05.06.2012].

Shaheen, M.E.K., Syef, M.A., Saha, S.S., Islam, M.S., Hossain, M.D.A., Sujan, M.A.I. and Rahmatullah, M. (2010). Medicinal plants used by the folk and tribal medicinal practitioners in two villages of Khakiachora and Khasia Palli in Sylhet district, Bangladesh. Advances in Natural and Applied Sciences, 5(1): 9-19.
Shah, S.F., Mubeen, S.M. and Mansoor, S. (2010). Concepts of homeopathy among general population in Karachi, Pakistan. J Pak Med Assoc, 60(8): 667-670.

Uddin, R., Saffoon, N. and Alam, M.A. (2011). Arsenic, the poison and poisoned groundwater of Bangladesh: A review. International Current Pharmaceutical Journal, 1(1): 12-17. [DOI]

Vyawahare, N., Pujari, R., Khsirsagar, A., Ingawale, D., Patil, M. and Kagathara, V. (2009). Phoenix dactylifera: An update of its indegenous uses, phytochemistry and pharmacology. The Internet Journal of Pharmacology 7(1). [DOI]

Ward, H., Mertens, T.E., Thomas, C. (1996). Health-seeking behavior and the control of sexually transmitted disease. Health Policy and Planning, 12: 19-28.

World Health Organization- WHO. (2008). Traditional medicine. [Link] [Accessed on 06.06.2012].

Yanan, H. (2009). Diarrhea in Bangladesh's capital on rise due to bad environment. Global times. [Link] [Accessed on 14.06.2012] 